\title{
Shortened Survival of Fetal Erythrocytes in the Rat
}

\author{
STEPHEN A. LANDAW $W^{(19)}$ \\ WITH THE TECHNICAL ASSISTANCE OF ROBERT L. GUANCIAL \\ Veterans Administration Hospital and the Departments of Medicine \& Radiology, SUNY-Upstate Medical Center,
} Syracuse, New York, USA

\section{Summary}

One to 4 days before birth of their litters, pregnant buffalo rats were injected intravenously with $200 \mu \mathrm{Ci}$ of $\left[2-{ }^{14} \mathrm{C}\right]$ glycine in order to label a cohort of fetally produced red blood cells (RBC). Shortly after birth, the newborn rats were transferred to noninjected foster mothers, and RBC survival was determined by the rate of production of ${ }^{14} \mathrm{CO}$ in the expired air of the newborn animals. In separate experiments, pregnant rats were injected 1-2 days before birth of their litters; blood was collected from the newborn at 5 days of age, washed, transfused into normal adult hosts, and RBC survival determined from the resultant ${ }^{14} \mathrm{CO}$ production. When compared with adult $\mathrm{RBC}$, in situ survival of fetally produced RBC was $22 \%$ of normal (mean life span of 12.1 days in the fetus, and $54.5 \pm 1.5$ (SE) days in the adult). This shortening of survival resulted from an acceleration of RBC senescence (15.7 days for fetal RBC and 66.2 \pm 0.7 days for adult $\mathrm{RBC}$ ) and an increased rate of random hemolysis $(3.70 \% /$ day in the fetal $\mathrm{RBC}$ and $0.67 \pm 0.07 \% /$ day in adult RBC). Although cross-transfusion of adult RBC into compatible adult rat hosts resulted in only a modest shortening of RBC lifespan (mean $R B C$ survival reduced from $54.5 \pm 1.5$ days to $52.8 \pm 0.8$ days), similar treatment of fetally produced RBC resulted in a marked acceleration of senescence from 15.7 days to 5.8 days. Examination of the RBC survival curves for those litters injected less than $72 \mathrm{hr}$ before birth indicated the presence of an additional population of cells with survival in the range of 25-40 days. The proportion of cells surviving longer than the major cohort (but shorter than times characteristic of adult $\mathrm{RBC}$ ) increased as the time interval between isotope injection and birth decreased.

\section{Speculation}

The magnitude of the shortening in survival noted for fetal RBC suggests the presence of structural and/or metabolic alterations peculiar to these cells, rather than alterations secondary to increased erythropoietic rate alone.

Numerous studies have shown shortened survival for RBC of full term and premature infants. For cord RBC of premature infants, ${ }^{51} \mathrm{Cr}$ half-times in adult hosts average $16-17$ days, as compared with values of 18-27 days for cord RBC of full term infants, and $24-32$ days for adult $\operatorname{RBC}(14,17)$. Full interpretation of this ${ }^{51} \mathrm{Cr}$ data is complicated by the lack of steady state conditions in such newborns, their young RBC population, and possible variations in the rate of label elution. However, cohort labeling with ${ }^{59} \mathrm{Fe}(5)$ and $\left[{ }^{15} \mathrm{~N}\right]$ glycine (16) confirmed the reduced survival of such cells. Similar shortening of survival was suggested for fetal RBC by following the rate of fall of fetal hemoglobin levels in fully compatible mothers autotransfused during the prenatal period $(4,15)$.

Recent studies of RBC destruction in the newborn dog (12) suggest a rapid elimination of fetally produced $\mathrm{RBC}$ during the immediate postnatal period. Since RBC survival is shorter in the premature infant than in the full term, and appears to decrease with decreasing birth weight (7), it has been concluded that RBC produced before birth have a markedly shortened survival, whereas those produced after birth have either slightly shortened or normal survival (2). The present study was undertaken in order to test this assumption by following the in situ survival of $\mathrm{RBC}$ produced in utero, using a noneluting cohort technique.

\section{MATERIALS AND METHODS}

All studies were performed in specific pathogen-free highly inbred buffalo rats (Simonsen Laboratories, Gilroy, Calif.). Pregnant rats were injected intravenously with $200 \mu \mathrm{Ci}$ of [2${ }^{14} \mathrm{Clglycine}$ (New England Nuclear, Boston, Mass.) under light ether anesthesia 24-96 hr before birth of their litters. Timing of these injections was facilitated by knowledge of the time of appearance of a vaginal postcoital plug. However, the variation in delivery times for animals with similar appearance times of vaginal plugs indicated that frequent abdominal palpation and inspection was a more reliable indicator of impending delivery.

After birth of the litters, the radioactive mothers were replaced by noninjected female rats which had also delivered litters within the preceding $24 \mathrm{hr}$. After a short period of adaptation in a darkened quiet area, the suckling radioactive litters and the nonradioactive foster mothers were studied as a group in the metabolism chamber system (see below). All such litters were accepted by the foster mothers and gained weight normally, without loss of animals from cannibalism.

For the study of RBC lifespan, the foster mother and litter were placed as a group in a darkened metabolism chamber containing bedding, food, and water. Air exiting from the chamber was assayed for ${ }^{14} \mathrm{CO}$ by methods previously described (11), and was calculated in terms of disintegrations per min $\cdot h r$. Red blood cell survival was calculated by computer analysis of the curves of ${ }^{14} \mathrm{CO}$ production versus time after isotope injection $(10,11)$. In this glycine-CO method, isotope is incorporated into heme, and is metabolically converted to ${ }^{14} \mathrm{CO}$ when such heme is degraded in vivo. The ${ }^{14} \mathrm{CO}$ thus formed, representing mole for mole the destruction of labeled heme, is excreted intact in the breath. Prior studies in adult and newborn rats have shown that ${ }^{14} \mathrm{CO}$ arising from degradation of nonhemoglobin heme and ineffective erythropoiesis (the "early labeled peak") appears almost exclusively during the first 2-3 days after isotope injection $(9-11)$. The production of ${ }^{14} \mathrm{CO}$ more than 3 days after 
isotope injection thus represents the instantaneous destruction of circulating $\mathrm{RBC}$, and can be used to determine erythrocyte survival $(10,11)$. This method avoids blood sampling, and is independent of alterations in blood volume, since it measures total labeled heme degradation. As a cohort technique, it also avoids the problems inherent in ${ }^{51} \mathrm{Cr}$ and $\left[{ }^{32} \mathrm{P}\right]$ difluorophosphate methods in which cells of all ages are labeled, and in which variable label elution may occur.

For cross-transfusion studies, three pregnant rats were injected intravenously with $200 \mu \mathrm{Ci}$ each of $\left[2-{ }^{14} \mathrm{C}\right] \mathrm{glycine}$ before birth of their litters. When the litters were 5 days old, blood was collected by decapitation and bleeding into vials of cold Hanks' buffered saline solution. The blood obtained from each litter was washed three times in cold Hanks' solution, diluted to a total of $2.5 \mathrm{ml}$, and injected intravenously into each of three adult male buffalo rats. Survival of the RBC in these cross-transfused animals was calculated as for the in situ studies.

To facilitate graphic and mathematical analyses, curves of ${ }^{14} \mathrm{CO}$ production rate versus time after isotope injection were normalized for each litter, such that " $\mathrm{CO}$ production was 100 $\mathrm{dpm} / \mathrm{hr}$ 15-16 days after isotope injection. The available data was then pooled, with each data point representing the mean of normalized ${ }^{1+} \mathrm{CO}$ production from at least five of the eight available litters (Fig. 1) or for at least three of the four available litters (Fig. 2).

\section{RESULTS}

Figure 1 indicates ${ }^{14} \mathrm{CO}$ production as a function of time after isotope injection for the 8 litters injected in utero, as well as for three normal adult male rats of the same strain (11). For the adult animals, peak ${ }^{14} \mathrm{CO}$ production at 65 days after isotope injection represents death by senescence of the RBC cohort. For the studies in which labeled glycine was injected in utero, the curve for ${ }^{14} \mathrm{CO}$ production is markedly shifted and skewed, indicating a shortened mean potential lifespan (acceleration of senescence) and increased random destruction. Computer evaluation of this data (11) indicated that the mean overall lifespan of RBC produced in utero is 12 days, or about $22 \%$ of that seen in the adult rat (Table 1). For the four litters injected $24-36 \mathrm{hr}$ before birth, the ${ }^{14} \mathrm{CO}$ excretion curve showed a secondary rise at about 25-35 days (Fig. 2, O). In contrast, the four litters injected 48-96 hours before birth had ${ }^{14} \mathrm{CO}$ excretion curves characteristic of a single cohort of RBC (Fig. 2, ๑). The magnitude of ${ }^{14} \mathrm{CO}$ excretion at 30-40 days in the litters injected $72-96$

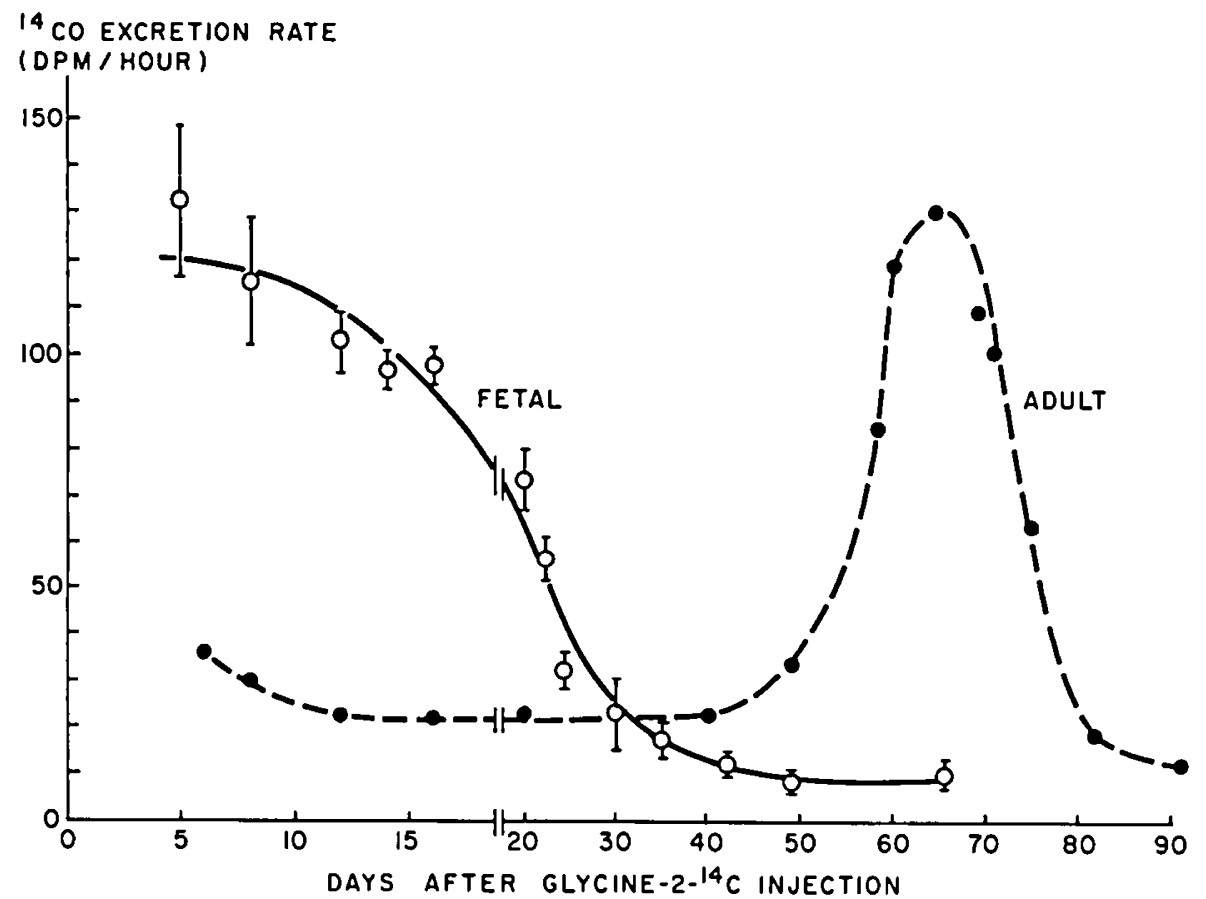

Fig. 1. Comparison of the survival of fetally labeled rat red blood cells $(\mathrm{RBC})(\mathrm{O}-\mathrm{O})$ with that of $\mathrm{RBC}$ produced in the adult rat $(\bullet---\bullet)$. Note the break in the graph at about 18 days. Confidence limits of the open circles represent $\pm 1 \mathrm{SE}$. The solid and dashed lines represent a computer-derived best fit of the given data points to appropriate equations representing the behavior of a single cohort of RBC (11). Best fit parameters for these curves are shown in Table 1.

Table 1. Comparison of red blood cell $(R B C)$ survival in the fetal and adult rat

\begin{tabular}{|c|c|c|c|c|}
\hline & \multicolumn{2}{|c|}{ Survival of fetal RBC } & \multicolumn{2}{|c|}{ Survival of adult RBC } \\
\hline & In situ & Cross-transfused & In situ & Cross-transfused \\
\hline No. of animals & 8 litters & 3 litters & 6 rats & 4 rats \\
\hline Mean potential RBC lifespan (days) & 15.7 & 5.8 & $66.2 \pm 0.7$ & $64.6 \pm 0.4$ \\
\hline $\begin{array}{l}\text { SD of lifespans about the mean potential lifespan } \\
\text { (days) }\end{array}$ & 10.8 & 5.3 & $7.6 \pm 0.6$ & $8.6 \pm 0.6$ \\
\hline $\begin{array}{l}\text { Fractional incorporation of glycine into RBC cohort } \\
\text { (\% of dose })\end{array}$ & 0.189 & & $0.247 \pm 0.032$ & \\
\hline
\end{tabular}

1 Mean \pm SE.

${ }^{2}$ Insufficient early data for exact determination. 
hr before birth was 7.5-11.5\% of maximal ("peak") values, in good agreement with the value of $8 \%$ expected from a single cohort of RBC having survival parameters as shown in Table 1 (first column). The magnitude of this additional ${ }^{14} \mathrm{CO}$ increased progressively as the time interval between isotope injection and birth decreased (Fig. 3 ).

The ${ }^{14} \mathrm{CO}$ data for the cross-transfusion studies is shown in Figure 4, and is compared with a survival curve obtained following cross-transfusion of adult buffalo rat $\mathrm{RBC}$ into separate adult buffalo rat hosts. For the latter, RBC lifespan is similar to that noted for the in situ studies, with a mean time of senescent RBC death of 65 days. For RBC labeled in utero $24-48 \mathrm{hr}$ before birth, and transfused into adults on the 5 th day of life, the ${ }^{14} \mathrm{CO}$

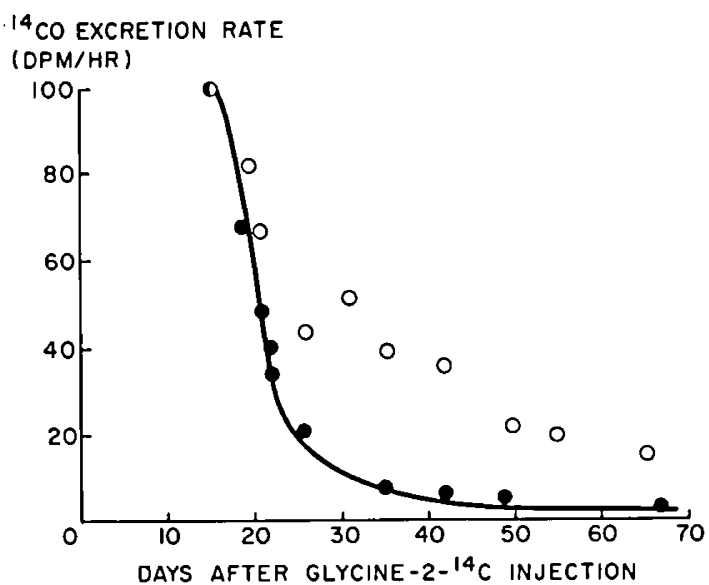

Fig. 2. Comparison of ${ }^{14} \mathrm{CO}$ excretion in four litters injected $24-36 \mathrm{hr}$ before birth $(O)$, with four litters injected $48-96 \mathrm{hr}$ before birth $(\bullet)$. Only the downslope of the ${ }^{14} \mathrm{CO}$ curve is shown, starting at 15-16 days postinjection, the time arbitrarily chosen for curve normalization (O). The solid line represents the computer-derived best fit as shown in Figure 1. Note the presence of a secondary rise in ${ }^{14} \mathrm{CO}$ excretion only for those red blood cell cohorts labeled $24-36 \mathrm{hr}$ before birth. data indicates a mean time of senescent death of not more than 6 days (approximately $12 \%$ of normal). There was no evidence for ${ }^{14} \mathrm{CO}$ production during the times characteristic of the death of adult RBC. However, when the computer-generated best fit ( - , Fig. 4) is compared with the actual data (O, Fig. 4), it can be seen that ${ }^{14} \mathrm{CO}$ production is greater than predicted during the time period 25-45 days postinjection, suggesting the production in the fetus of a small population of RBC with a lifetime longer than 20 days, but less than that characteristic of adult RBC. Computer analysis of this data (Table 1) indicates that collection, washing, and transfusion of the fetally produced RBC into

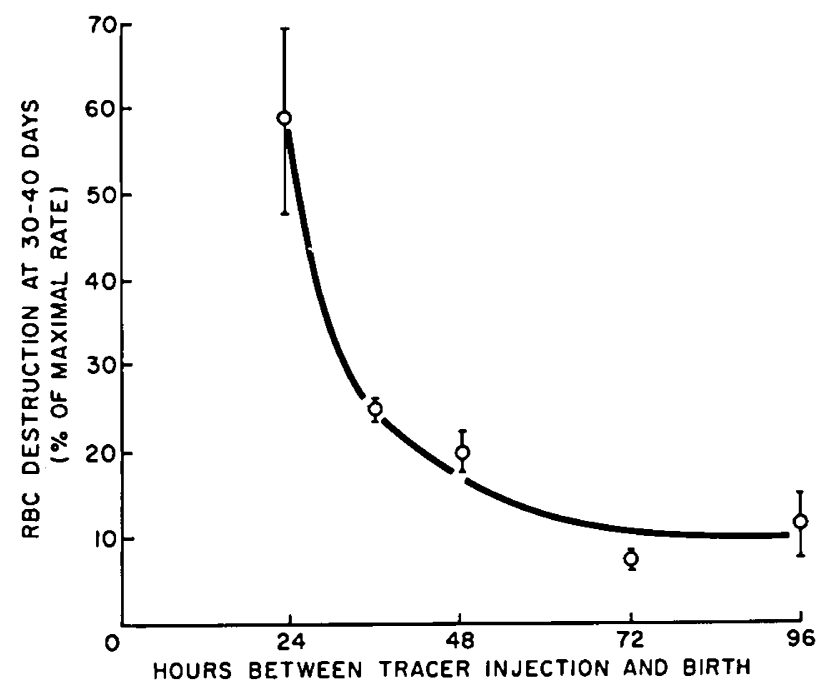

Fig. 3. Production of labeled carbon monoxide 30-40 days after isotope injection as a function of the time elapsing between isotope injection and birth. Red blood cell destruction is shown on the ordinate as the percent of maximal ${ }^{14} \mathrm{CO}$ production, while the interval (hours) between isotope injection and birth is shown on the abscissa. The confidence limits represent $\pm 1 \mathrm{SE}$ for at least two observations at each time period.

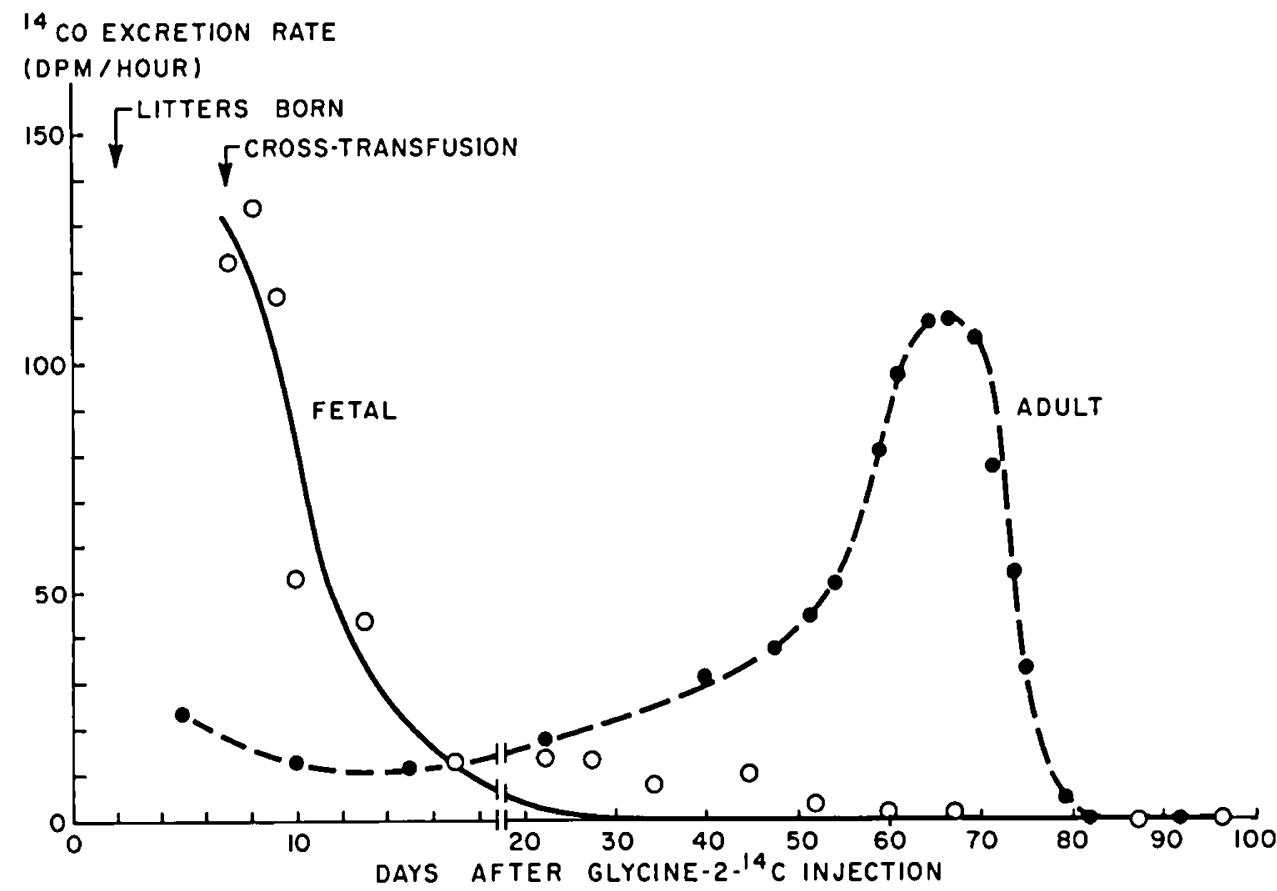

Fig. 4. Comparison of the survival of fetally labeled rat red blood cells $(\mathrm{RBC})(\mathrm{O}-\mathrm{O})$ with that of adult $\mathrm{RBC}(\bullet---\bullet)$ when cross-transfused into adult hosts. Note the break in the graph at about 18 days. The time of birth and cross-transfusion are shown for the fetally labeled RBC. Solid and dashed lines are as noted in Figure 1; best fit parameters for these two curves are given in Table 1. 
adult host compromises the survival of these cells to a greater extent than does similar handling of adult RBC. Whereas crosstransfusion of adult $\mathrm{RBC}$ results in less than $5 \%$ shortening of survival (11), similar treatment of fetally labeled RBC resulted in an acceleration of senescence from 16 days to less than 6 days, or a shortening in survival of at least $60 \%$.

\section{DISCUSSION}

These studies indicate that survival of RBC produced in utero in the rat is approximately $22 \%$ of that noted in adult rats because of accelerated senescence ( $24 \%$ of normal) and increased random hemolysis (5.5 times normal). That this altered survival is due to a defect intrinsic to the fetal RBC is indicated by the shortened survival of these cells when transfused into compatible adult rats.

When data from individual litters was analyzed separately, it was noted that litters born within 24-36 hr of injection of labeled glycine had evidence for an additional population of RBC with a lifespan in the range of 30 days (Fig. 2). For animals injected 72 $\mathrm{hr}$ or more before birth, ${ }^{14} \mathrm{CO}$ production $30-40$ days after isotope injection was equal to that expected from destruction of a single cohort. For those injected less than $72 \mathrm{hr}$ before birth, this additional ${ }^{14} \mathrm{CO}$ production increased progressively as the time interval between isotope injection and birth decreased (Fig. 3). Similar behavior can be seen for the cross-transfused RBC, since these were obtained from litters injected $24-48 \mathrm{hr}$ before birth (Fig. 4). Since in all cases maximal RBC destruction was found at 14-16 days after isotope injection, these data can be interpreted to mean that there is the appearance of a second cohort of RBC living longer than the mean, and that the size of this additional $R B C$ population increases progressively with advancing fetal age. A similarly skewed survival was predicted for the human newborn by Bratteby et al. (3). although these authors noted that their derived lifespan frequency function did not change appreciably during the last 60 days of fetal life.

Recent experiments (8) indicate that the survival of cohorts of $\mathrm{RBC}$ produced in 2-day-old rats is approximately twice that noted for fetal RBC (55\% of normal), whereas that for RBC formed in 5-10-day-old rats was approximately $75 \%$ of normal. Cross-transfusion studies of the latter RBC into adult hosts confirmed the longer survival as well as the intrinsic nature of the $\mathrm{RBC}$ defect. It can be concluded that survival of RBC is continuously improving during the last $96 \mathrm{hr}$ of fetal development in the rat, and rapidly improves towards normal following birth. These alterations in survival correlate with the progressive increase in body weight of the newborn rats, in agreement with observations by Kaplan and Hsu (7) for newborn man, as well as with the generally noted increase in RBC survival as a function of increasing body weight in the animal kingdom (1). Indeed, these studies document the shortest RBC survival for any normal mammalian species reported to date.

The marked degree of shortening of survival after cross-transfusion of fetal RBC suggests that these cells are more sensitive to in vitro manipulation than are comparably handled adult $\mathrm{RBC}$ $\mathrm{RBC}$. However, it is also possible that reticuloendothelial hypofunction in such fetal animals (6) may prolong the observed in situ survival, and that cross-transfusion into adults with normally functioning spleens uncovers the true magnitude of the RBC defect.

Previous studies in adult buffalo rats have confirmed the presence of accelerated RBC senescence with increasing erythropoietic rate (9). However, increases in erythropoietic rate up to 10 times normal following phlebotomy or phenylhdrazine treatment resulted in an acceleration of RBC senescence of not more than $20-35 \%$. This is of sufficient magnitude to explain the survival of RBC formed in 5-10-day-old rats, but is insufficient to explain the $76-91 \%$ acceleration of senescence noted for fetal $\mathrm{RBC}$ in this study. Therefore, one is tempted to conclude that the marked alterations in survival of fetal RBC primarily reflect metabolic and/or structural differences peculiar to fetal $\mathrm{RBC}$ (13), rather than alterations secondary to an increased erythropoietic rate $(2,14)$.

\section{CONCLUSION}

The survival of fetal $\mathrm{RBC}$ in the rat was studied by a cohort technique, employing the production of ${ }^{14} \mathrm{CO}$ in newborn litters following injection of labeled glycine into pregnant rats. Noninjected foster mothers replaced the originally injected mothers so that the only source of ${ }^{14} \mathrm{CO}$ would be from the degradation of heme labeled in utero. In eight litters injected 24-96 hr before birth, RBC senescence was noted to be markedly accelerated, and random hemolysis was increased, resulting in a mean overall RBC survival $22 \%$ of normal. Cross-transfusion of RBC labeled in utero into adult hosts confirmed the intrinsic nature of the defect in these cells. These studies appear to be the first direct testing of the survival of fetally produced RBC in an animal species, and confirm the general suspicion that the survival of such cells is markedly reduced.

\section{REFERENCES AND NOTES}

1. Allison, A. C.: Turnovers of erythrocytes and plasma proteins in mammals. Nature, 188: 37 (1960).

2. Bratteby, L.- E., and Garby, L.: Development of erythropoiesis: Infant erythrokinetics, In: D. G. Nathan and F. A. Oski, Editors: Hematology of Infancy and Childhood, p. 56 (Saunders, Philadelphia, 1974).

3. Bratteby, L.- E., Garby, L., Growth, T., Schneider, W., and Wadman, B.: Studies on erythrokinetics in infancy. XIII. The mean life span and the life span frequency function of red blood cells formed during foetal life. Acta Paediat. Scand., 57: 311 (1968).

4. Cohen, F., Zuelzer, W. W., Gustafson, D. C., and Evans, M. M.: Mechanism of isoimmunization. I. The transplacental passage of fetal erythrocytes in homospecific pregnancies. Blood, 23: 621 (1964)

5. Garby, L., Sjölin, S., and Vuille, J-C.: Studies on erythro-kinetics in infancy. V. Estimation of the life span of red cells in the newborn. Acta Paediat. Scand., 53: 165 (1964).

6. Holroyde, C. P., Oski, F. A., and Gardner, F. H.: The "pocked" erythrocyte. Red-cell surface alterations in reticuloendothelial immaturity of the neonate. New Engl. J. Med., 281: 516 (1969).

7. Kaplan, E., and Hsu, K. S.: Determination of erythrocyte survival in newborn infants by means of $\mathrm{Cr}^{5}$-labelled erythrocytes. Pediatrics, 27: 354 (1961).

8. Landaw, S. A.: Unpublished data.

9. Landaw, S. A.: Studies of heme metabolism using the endogenous production of carbon-14 labeled carbon monoxide (Ph.D. thesis, University of California, Berkeley, 1969).

10. Landaw, S. A.: Kinetic aspects of endogenous carbon monoxide production in experimental animals. Ann. N. Y. Acad. Sci., 174: 32 (1970).

11. Landaw, S. A., and Winchell, H. S.: Endogenous production of "CO: A method for calculation of RBC life-span in vivo. Blood, 36: 642 (1970).

12. Lee, P., Brown, M. E., and Hutzler, P. T.: Blood volume changes and production and destruction of erythrocytes in newborn dogs. Amer. J. Vet. Res., 37: 561 (1976).

13. Oski, F. A., and Komazawa, M.: Metabolism of the erythrocytes of the newborn infant. Sem. Hematol., 12: 209 (1975).

14. Pearson, H. A.: Life-span of the fetal red blood cell. J. Pediat., 70: 166 (1967).

15. Pearson, H. A., and Diamond, L. K.: Fetomaternal transfusion. A. M. A. J. Dis. Child., 97: 267 (1959).

16. Vest, M., Strebel, L., and Hauenstein, D.: The extent of "shunt" bilirubin and erythrocyte survival in the newborn infant measured by the administration of $\left({ }^{15} \mathrm{~N}\right)$ glycine. Biochem. J., 95: 11c (1965).

17. Zipursky, A.: The erythrocytes of the newborn infant. Sem. Hematol., 2: 167 (1965).

18. This work was supported by the Medical Research Service of the Veterans Administration (Project no. 5134-01)

19. Requests for reprints should be addressed to: S. A. Landaw, M.D., Associate Chief of Staff, Research, V.A. Hospital, Irving Ave. and University Pl., Syracuse, N. Y. 13210 (USA)

20. Received for publication January 4, 1977.

21. Accepted for publication March 15, 1977. 